\title{
The role of allogeneic stem cell transplantation in the therapy of adult acute lymphoblastic leukemia
}

\author{
O papel do transplante alogênico de células progenitoras na terapia de leucemia linfoblástica \\ aguda em adultos
}

Partow Kebriaei, M.D. ${ }^{\text {I }}$

Richard Champlin, M.D.

\begin{abstract}
While adult patients with acute lymphoblastic leukemia (ALL) can now achieve complete remission (CR) rates of up to $90 \%$ with intensive chemotherapy regimens, only $25-50 \%$ of these patients remain in long-term remission. Current research efforts are focused on innovative post-remission strategies with the goal of improving disease-free (DFS) and overall survival (OS). The identification of different prognostic groups based on the biology of the malignant clone and clinical patterns of disease presentation allows for risk-adapted therapy. Multiple randomized trials have demonstrated that hematopoietic stem cell transplantation (SCT) improves the outcome of patients with high-risk ALL. Among high-risk patients, the presence of disease at time of stem cell transplantation, and the source of stem cells used have great impact on survival. The incorporation of monoclonal antibodies into the transplant preparative regimen may improve transplant efficacy. The use of donor lymphocyte infusions (DLI) is still under investigation in this patient population. Rev. bras. hematol. hemoter. 2005;27(1):61-69.
\end{abstract}

Key words: Acute lymphoblastic leukemia; allogeneic stem cell transplantation; prognostic factors.

\section{Introduction}

Adult patients with acute lymphoblastic leukemia (ALL) can now achieve complete remission (CR) rates of $80-90 \%{ }^{1-3}$ However, only $25-50 \%$ of these patients remain in remission. Current research efforts are focused on innovative post-remission strategies with the goal of improving disease-free (DFS) and overall survival (OS). The identification of different prognostic groups based on the biology of the malignant clone and prognostic factors allows for risk-adapted therapy. Multiple randomized trials have demonstrated that hematopoietic stem cell transplantation (SCT) improves the outcome of patients with high-risk ALL. In this review, we will define the different disease risk groups, the clinical outcomes of major transplant trials for ALL, and the therapeutic factors that affect outcome after SCT.

\section{Prognostic factors in adult All}

Several biologic features and specific clinical characteristics have been consistently noted to influence the outcome of adult ALL and impact on risk-stratification (Figure 1). Older age, an elevated white blood cell count (WBC) at presentation, and failure to achieve a clinical remission within the first four weeks of treatment are generally

Figure 1. Adverse prognostic features in adult ALL

- Age greater than 60 years*

- WBC count greater than 30,000/uL

- Cytogenetics: $\mathrm{t}(9 ; 22)(\mathrm{q} 34 ; \mathrm{q} 11)$, trisomy 8 , $\mathrm{t}(4 ; 11)(\mathrm{q} 21 ; \mathrm{q} 23)$, monosomy 7 , a hypodiploid karyotype, $t(1 ; 19)(q 23 ; p 13)$ - Delayed time to complete remission, greater than 4 weeks

*Established in US series; German series use age 30-, 35-, or 50 years as cut-off.

\footnotetext{
${ }^{I}$ Department of Blood and Marrow Transplantation, University of Texas - M.D. Anderson Cancer Center, Houston, Texas, USA

Correspondence: Partow Kebriaei, $M D$

Anderson Cancer Center, 1515 Holcombe Boulevard, Unit 423, Houston, TX 77005

E-mail: pkebriae@mdanderson.org
} 
accepted adverse clinical features. The detection of specific recurring cytogenetic abnormalities has emerged as the most important prognostic factor for risk stratification of adults with ALL. ${ }^{4}$ Clonal chromosomal aberrations can be detected in cells from $62 \%$ to $85 \%$ of adult ALL patients, and numerous studies have shown their significance as predictors of outcome. . $^{5-8}$

In addition to the adverse prognostic factors listed in Figure1, the detection of minimal residual disease (MRD) using qualitative or semi-quantitative polymerase chain reaction (PCR) or flow cytometric techniques also provides important prognostic information. ${ }^{9}$ Persistent MRD positivity post induction appears to be associated with an increased risk of relapse. ${ }^{10}$ In addition, MRD positivity after transplant is associated with an increased risk of relapse. In $28 \mathrm{Ph}+\mathrm{ALL}$ patients, Radich et al found that the relative risk (RR) for relapse was significantly higher for patients with a detectable $\mathrm{BCR} / \mathrm{ABL}$ transcript following transplantation than for those without detectable $B C R / A B L(\mathrm{RR}=5.7, \mathrm{p}=0.025) .{ }^{11}$ Furthermore, the risk of relapse was greater for patients with a p190 fusion transcript than for those with p210 BCR/ABL. The median time from detection of a positive PCR result to relapse was 94 days. Other investigators have found similar results. ${ }^{12-15}$

\section{Results with Allogeneic Transplantation for High-risk ALL}

\section{First complete remission}

Review of a number of small, phase II trials in high-risk adult ALL who have undergone ASCT in CR1 suggest a higher DFS when compared with historic controls based on conventional chemotherapy. ${ }^{16-22}$ High-risk in these studies was defined as patients having at least one or more of the following: age greater than 30 years, WBC greater than $30 \times 10^{9} / \mathrm{L}$ at presentation, extramedullary disease, unfavorable cytogenetic abnormalities, and requiring more than four weeks to achieve CR. As shown in Table 1, DFS ranges broadly from $21 \%-71 \%$, with a 3 to 8 year follow-up. The large difference in the outcome of these phase II studies is influenced by multiple variables, including differences in patient selection, type of graft versus host disease (GVHD) prophylaxis, and different supportive care regimens. The choice of preparative regimen may have played a smaller role since all received a total body irradiation (TBI)-based conditioning regimen.

Two large, prospective controlled trials have directly compared transplant with chemotherapy in patients in CR1. The French Leucemie Aigue Lymphoblastique de l'Adulte LALA 87 protocol was a cooperative study that examined the role of chemotherapy and SCT for adult ALL patients. This was a prospective, randomized study, initiated in November 1986 and completed in July 1991, which enrolled 634 newly diagnosed patients (572 patients after exclusions) and reported 10 year follow-up results. The median age of patients entered onto this trial was 33 years. All patients received standard induction therapy and CNS prophylaxis. Among those patients who achieved CR (76\%), patients greater than 50 years-old received post-remission chemotherapy, those up to the age of 40 continued to a TBI-based allogeneic SCT if they had a histocompatible donor, and all others were further randomized to consolidation chemotherapy followed by long-term maintenance therapy, or autologous SCT. Survival at 10 years was significantly greater for the allogeneic SCT group compared to consolidation chemotherapy (46\% SCT vs. $31 \%$ chemotherapy, $\mathrm{p}=0.04)$. Furthermore, when these groups were stratified into high and standard risk, there was a highly significant benefit for allogeneic SCT in the high risk subset (high-risk: $44 \%$ SCT, $11 \%$ chemotherapy, $\mathrm{p}=0.009$; standardrisk: $49 \% \mathrm{SCT}, 43 \%$ chemotherapy, $\mathrm{p}=0.6) .{ }^{23,24}$ There was no statistically significant difference in outcome between patients who received autologous SCT vs. consolidation chemotherapy (34\% SCT, 29\% chemotherapy, $\mathrm{p}=0.6)$. Risk stratification did not change these findings.

The United Kingdom Medical Research Council's (MRC) UKALL XII/Eastern Cooperative Oncology Group (ECOG) E2993 is also conducting a prospective trial to define the role of allogeneic SCT, autologous SCT, and conventional dose chemotherapy in adult patients with ALL in CR1. Initiated in 1993, over 1200 patients have been enrolled to date. All patients received two phases of induction therapy, and continued to allogeneic SCT if they 
achieved $\mathrm{CR}$ and had a histocompatible donor. The remaining patients were randomized to standard consolidation/ maintenance therapy for 2.5 years vs. a single autologous SCT. The conditioning regimen for both allogeneic and autologous transplants was fractionated TBI (1320 cGy) and $\mathrm{VP}-16(60 \mathrm{mg} / \mathrm{kg})$. Based on the data presented in an abstract in 2001, ${ }^{25} 239$ patients received an allogeneic SCT (170 Ph-) and 291 patients received chemotherapy or autologous SCT. The overall event free survival (EFS) for the allogeneic SCT group was $54 \%$ vs. $34 \%(\mathrm{p}=.04)$ for the chemotherapy or autologous BMT group. Excluding the $\mathrm{t}(9 ; 22)$ karyotype, when patients were stratified into high or standard risk, the difference in EFS becomes more dramatic in the high risk subset (allogeneic BMT 44\% vs. chemo./autologous BMT $26 \%, p=.06$ ). In conclusion, both of these large prospective controlled studies determined that allogeneic SCT improved the outcome for adults with high-risk ALL in CR1.

\section{Beyond CR1}

There are no data suggesting that durable remissions can be achieved with standard chemotherapy for adults with ALL who fail to achieve an initial complete remission or have recurrent disease. Second complete remissions can often be achieved, but are typically of shorter duration than the initial response. Patients who undergo an allogeneic SCT in CR2 have achieved long-term leukemia-free survival (LFS) rates between $14 \%$ to $43 \%$, as illustrated in Table $2 .{ }^{19,22,26-29}$ Therefore, if patients are in remission, allogeneic SCT results in greater LFS when compared to chemotherapy. The primary cause of failure is relapse $(>50 \%)$.

\section{Primary refractory ALL}

With current induction regimens, only $5-10 \%$ of adults with newly diagnosed ALL fail to achieve remission with initial induction chemotherapy. These patients often have poor prognostic factors at presentation, and additional attempts at induction chemotherapy are usually of limited benefit. Several studies suggest that patients with an HLA identical sibling benefit by receiving allogeneic transplantation without undergoing a second attempt at induction therapy. ${ }^{30-32}$ In the largest of these studies, 38 patients with ALL failing to achieve remission received HLA identical sibling transplants.

Table 2. Allogeneic Transplantation for ALL in CR2

\begin{tabular}{cccc}
\hline Study & No.Pt. & LFS (\%) & $\begin{array}{c}\text { Risk of } \\
\text { Relapse }\end{array}$ \\
\hline IBMTR, 198927 & 208 (high risk) & $22(4 \mathrm{yr})$ & 56 \\
& 97 (standard ris) & $36(4 \mathrm{yr})$ & 49 \\
Barrett, 198928 & 391 & $26(5 \mathrm{yr})$ & 52 \\
Wingard, 199023 & 36 & $43(5 \mathrm{yr})$ & 26 \\
Doney, 199120 & 48 & $15(5 \mathrm{yr})$ & 64 \\
Greinix, 1998 & 27 & $14(3 \mathrm{yr})$ & 78 \\
Michallet, 2000 & 47 & $44+/-12 \%$ & $44+/-12 \%$
\end{tabular}

Approximately $35 \%$ of these patients with refractory disease became long-term disease-free survivors. In a retrospective review of patients with primary refractory and relapsed ALL, the records of 314 adults were reviewed for disease outcome at MD Anderson Cancer Center between 1980 and 1997. Allogeneic SCT was performed in 29 patients (13 in salvage and 16 in CR2). The rates for durable CR post transplant were comparable between the two groups; $5 / 13(38 \%)$ in the salvage group and 5/16 (31\%) in the remission group. Although patient numbers are small and a variety of transplant conditioning regimens were used, these results corroborate the findings of earlier studies, and suggest that allogeneic transplant should be considered for these patients with an otherwise dismal chance of long-term survival. ${ }^{33,34}$

\section{Philadelphia Chromosome Positive All}

$\mathrm{Ph}+$ acute lymphoblastic leukemia is well established to have a very poor prognosis. The recent incorporation of imatinib mesylate into combination chemotherapy has been a major development. Imatinib is a highly effective, targeted therapy directed against the $B C R / A B L$ tyrosine kinase that is over-expressed as a result of the $\mathrm{t}(9 ; 22)(\mathrm{q} 34 ; \mathrm{q} 11)$ in chronic myeloid leukemia and $\mathrm{Ph}+\mathrm{ALL} .{ }^{33}$ The rapid initial response to therapy and minimal side effects make imatinib an ideal drug for incorporation into clinical trials for treatment of newly diagnosed $\mathrm{Ph}+\mathrm{ALL}$. In a study by Thomas et al, 20 patients with newly diagnosed $\mathrm{Ph}+\mathrm{ALL}$ received concurrent hyperCVAD (cyclophosphamide, vincristine, Adriamycin, dexamethasone) and imatinib at the $400 \mathrm{mg}$ dose. All patients achieved CR. Ten patients received allogeneic SCT in first CR within a median of 3.5 months, with 9 remaining alive in CR with a median follow-up of 12 months. ${ }^{35}$ Although this is an early study with very short follow-up, these results are very encouraging for a subset of patients with a traditionally very poor prognosis.

Data from the MRC UKALL XII/ECOG E2993 study described earlier revealed similar poor results for $\mathrm{Ph}+$ patients treated with chemotherapy only. In this on-going, prospective, randomized study, $167 \mathrm{Ph}+$ patients were treated on the MRC UKALL XII/ECOG E2993 protocol between 1993 and 2000. Seventy-two patients received a matched-related or unrelated donor transplant in CR1, while 7 received an autologous transplant and 88 received chemotherapy due to lack of donors. As expected, the 5year EFS and OS were significantly higher for the allogeneic transplant group, $36 \%$ and $42 \%$, respectively, compared to $17 \%$ and $19 \%$ for the nonallogeneic transplant groups. ${ }^{36}$ These results suggest that the presence of the $\mathrm{Ph}$ chromosome is most detrimental to maintaining long-term remission, and underscore the need for long-term follow-up of ongoing studies with imatinib. Until long-term results are obtained, all $\mathrm{Ph}+$ patients should still receive an allogeneic SCT in CR1 if a donor is available. 
Table 3. Allogeneic Transplantation for Ph+ ALL

\begin{tabular}{ccccc}
\hline Study & No. Pt. & $\begin{array}{c}\text { Med. Age } \\
\text { (Yr.) }\end{array}$ & $\begin{array}{c}\text { Prep. } \\
\text { Regimen }\end{array}$ & 3-Yr.DFS\% \\
\hline $\begin{array}{c}\text { Stockschlader, } \\
1995^{39}\end{array}$ & 10 & 31 & VP-16/CY/TBI & 46 \\
$\begin{array}{c}\text { Dunlop, 1996 } \\
\text { Sn }\end{array}$ & 11 & 27 & TBl-based & 21.8 \\
Snyder,199938 & 23 & 30 & VP-16/fTBI & $\begin{array}{c}\text { 65 (SCT before 1992) } \\
\text { 81 (SCT after 1992) }\end{array}$ \\
\hline
\end{tabular}

CY, cyclophosphamide; TBI, total body irradiation; fTBI, fractionated TBI ;

VP-16, etoposide

Disease outcome from a series of single-center retrospective studies are listed in Table $3 .{ }^{18,37-39}$ It is difficult to draw conclusions from these small series that vary considerably with respect to type of patient (CR1 or beyond), type of preparative regimen, GVHD prophylaxis, and supportive care. The reported DFS rate varies widely between $20 \%$ to $80 \%$, and it is difficult to determine if a particular preparative regimen is superior. Generally, data from most series suggest that $\mathrm{Ph}+$ patients fare best when transplanted in CR1. Follow-up from the prospective MRC UKALL XII/ ECOG E2993 study is eagerly anticipated. Trials incorporating novel agents such as imatinib mesylate, or using reduced intensity preparative regimens, are currently in progress, and these results are also anticipated.

The feasibility of alternative donor transplants has been investigated in $\mathrm{Ph}+\mathrm{ALL}$ patients in efforts to provide allogeneic transplantation to patients who lack a matched sibling. At the Fred Hutchinson Cancer Research Center, matched unrelated donor (MUD) transplantation was investigated in 18 patients with Ph+ ALL between 1988 and 1995 , and the probability of LFS at 2 years was $49 \%$, similar to rates reported for matched sibling-SCT. ${ }^{40}$ However, it must be emphasized that this was a highly selected population of relatively young patients. Too few adults with $\mathrm{Ph}+\mathrm{ALL}$ have received cord blood or haploidentical donor transplants to comment on results.

Donor lymphocyte infusion (DLI) has also been investigated in patients with $\mathrm{Ph}+\mathrm{ALL}$, and shows very limited efficacy, ${ }^{41,42}$ in contrast to $\mathrm{Ph}+\mathrm{CML}$. It is not known whether this disparity in efficacy stems from differences in the immunogenicity of the $\mathrm{p} 190 \mathrm{BCR} / \mathrm{ABL}$ (most $\mathrm{Ph}+\mathrm{ALL}) \mathrm{vs}$. the p210 BCR/ABL (most CML), differences in growth kinetics of $\mathrm{Ph}+\mathrm{ALL}$ relapse (high tumor burden) vs. those in CML (lower tumor burden), or other disease specific factors.

\section{Factors Influencing Transplant Outcome}

\section{Preparative Regimens}

Radiation-based

Several different preparative regimens for allogeneic SCT have been described in attempts to decrease transplant related mortality (TRM) and improve DFS. The most widely used regimen is the combination of total body irradiation (TBI) and cyclophosphamide developed by Thomas and colleagues. TBI can be administered as single dose, or fractionated over 35 days. A comparative analysis of fractionated-dose vs. single-dose TBI in adult ALL patients showed a significantly higher TRM in the single-dose group $(p=0.017)$, but an increase in the relapse rate of the fractionated-dose group; consequently, there were no differences in the overall LFS between the 2 groups. ${ }^{20}$ The Minnesota Group compared TBI/ cyclophosphamide with TBI/Ara-C in a study including both adults and children, and found no outcome difference in regards to toxicity or outcome. ${ }^{43}$ The City of Hope group studied fractionated TBI with etoposide followed by SCT in patients with advanced leukemia. A Phase I/II trial indicated that etoposide at $60 \mathrm{mg} / \mathrm{kg}$ is the maximum tolerated dose when combined with TBI. In that study, 36 ALL patients were treated; 20 had relapsed disease. The DFS was $57 \%$, with a $32 \%$ relapse rate suggesting that the regimen has significant activity in advanced ALL. ${ }^{44}$

Novel methods to allow selective delivery of radiation to sites of leukemia without increasing systemic toxicity are currently under investigation. One method with great potential is the incorporation of radiolabeled monoclonal antibodies (MoAb) into the conditioning regimen. Preliminary results from Phase I trials are intriguing. ${ }^{45,46}$ The ultimate benefits of this approach with respect to safety and improvements in survival will be defined by Phase II studies.

\section{Non-radiation based preparative regimens}

Non-radiation containing regimens, most commonly busulfan and cyclophosphamide have been investigated in hopes of decreasing radiation-related complications. Fractionated TBI/etoposide was compared with busulfan/ cyclophosphamide in a prospective, randomized study conducted by the Southwest Oncology Group (SWOG 8612). There was no significant difference with respect to toxicity, incidence of acute GVHD, OS or DFS between the two groups. The leading cause for treatment failure was leukemic relapse $(39 \%) .{ }^{56}$ Furthermore, retrospective analysis of registry data from the International Bone Marrow Transplant Registry (IBMTR) shows similar rates for LFS and relapse when busulfan/cyclophosphamide is compared to TBI/ cyclophosphamide. ${ }^{47}$

The addition of monoclonal antibodies to the transplant conditioning regimen is another method of developing potentially more effective, and less toxic, regimens. Antibody therapy is generally considered to be an option when the target antigen is expressed on at least $30 \%$ of the targeted cells. ${ }^{48}$ ALL blasts express a variety of B- or T-cell differentiation antigens, such as CD19, CD20, CD22, CD33, and CD52, which can serve as targets for directed therapy. ${ }^{48}$ 
Phase I data are available for antibody therapy directed against CD19, CD20, and CD52, and suggest that antibodies should be used as an adjunct to chemotherapy. The efficacy for Moabs as monotherapy is limited, especially in the setting of overt relapse or rapidly progressive disease. ${ }^{49,50}$ Definitive data from Phase II and III trials are pending.

Campath-1H, a humanized MoAb developed against the CD52 antigen, is particularly interesting since it targets a subset of ALL for disease eradication, as well as provides a novel method of T-cell depletion to prevent GVHD in the allogeneic transplant setting. Novitzky et al evaluated 13 patients with ALL ( 8 in CR1) and 37 patients with AML (33 in CR1), who had undergone HLA-identical sibling transplants. The conditioning regimen consisted of TBI/cyclophosphamide. Bone marrow or PBSC were exposed to CAMPATH-1H ex-vivo. Patients received no post-transplant immunosuppression. All but 1 patient engrafted, and only $22 \%$ of all patients developed grade I or II GVHD; there was no severe GVHD. There is concern that the immunosuppressive effect of Campath-1H may inhibit the immune graft-vs-malignancy effect and 54\% (7/13) of the ALL patients on this study relapsed. ${ }^{51}$ Large, randomized studies will be required to determine whether inclusion of Campath- $1 \mathrm{H}$ will improve the overall outcome for patients undergoing transplantation for ALL.

\section{Non-myeloablative SCT (NMSCT)}

Numerous studies have now demonstrated successful donor stem cell engraftment with NMSCT for hematologic and solid organ malignancies. These regimens use reduced doses of chemotherapy +/- low dose TBI as immune suppression to prevent graft rejection and allow development of an immune graft-vs-malignancy (GVM) effect. GVM appears to be operative against ALL; the major evidence being a reduced rate of relapse in patients who have GVHD. However, ALL appears less effected by GVM than the other major forms of leukemia and the role of NMSCT requires further evaluation. The major benefit of NMSCT is a lower risk of drug toxicity and treatment related morbidity and mortality, which is most relevant to older or debilitated patients unable to tolerate ablative preparative regimens. This option would be particularly attractive for patients with $\mathrm{Ph}+\mathrm{ALL}$ where the majority of patients are older than 50 years.

Martino et al reported on the largest published cohort of adult ALL patients receiving NMSCT. ${ }^{52}$ He analyzed the results of 27 patients with high-risk ALL that were included in 4 prospective studies. Similar to other reduced-intensity transplant series, these were older patients with advanced disease. The median age was 50 years; 23 (85\%) patients were beyond CR 1, 44\% were chemorefractory, and $41 \%$ were $\mathrm{Ph}+$. Donors were mismatched related donors or volunteer unrelated donors in 12 cases (44\%). The incidence of grades II-IV acute GVHD was $48 \%$, and 13 of 18 evaluable patients (72\%) developed chronic GVHD. With a median follow-up of
809 days, the incidence of TRM was $23 \%$, the probability of OS was $31 \%$, and the incidence of disease progression was $49 \%$ at 2 years. The incidence of disease progression in patients with and without GVHD, $35 \%$ and $47 \%$, respectively, approached statistical significance $(\mathrm{p}=0.05)$. The incidence of disease relapse was $33 \%$ in patients transplanted in CR compared to $60 \%$ in those with overt disease.

These observations for NMSCT must be validated in well-defined prospective trials. NMSCT, as an immunotherapeutic approach, is probably most appropriate in patients with low bulk disease. In this study, and others, a higher relapse rate was observed for patients transplanted with overt disease. ${ }^{53}$ Thus, NMSCT does not appear indicated for patients with overt relapsed or resistant ALL. The initial studies appear most promising for older patients transplanted in remission, and the reported OS and TRM rates were quite favorable considering the advanced disease state of the patients and the number of unrelated transplants included in this series. Thus, it is reasonable to enroll older patients (age $>50$ years) and those with a high risk of TRM onto prospective studies of NMSCT. Younger allogeneic transplant candidates without major comorbidities, should still receive high dose therapy with ablative preparative regimens, as established effective treatment for ALL.

\section{Source of Stem Cells}

Bone marrow vs. peripheral blood stem cells

Bensinger et al published a prospective, randomized trial comparing bone marrow (BM) to peripheral blood as the source of stem cells. It was concluded from this study that allogeneic PBSC result in faster engraftment without an increased risk of GVHD (median day to neutrophil recovery defined as $>500 / \mathrm{mm}^{3}, 16$ vs. 21 , p-value $<0.001$; median day to platelet recovery defined as $>20,000 / \mathrm{mm}^{3}, 13 \mathrm{vs} .19$, p-value $<0.001)$. It was also observed that patients who received PBSC had a lower incidence of relapse at 2 years, and higher OS and DFS. ${ }^{51}$ While similar subsequent series have confirmed that PBSC result in faster engraftment, a large retrospective analysis from the IBMTR and EBMT showed that the incidence of chronic GVHD was significantly higher with the use of PBSC ( $65 \%$ vs. $53 \%, p=0.02)$. In addition, the risk of relapse was not significantly different between these two groups. ${ }^{54}$ Thus, a large, multicenter, prospective study was developed to help define the role of PBSC in allogeneic SCT. In this collaborative effort by the BMT-CTN, adult leukemia patients requiring MUD transplantation will be randomized to BM or PBSC donors. Results of this trial are eagerly anticipated.

\section{Umbilical Cord Blood (UCB)}

Recently, UCB transplantation (UCBT) is beginning to emerge as a viable, alternative hematopoietic stem cell source for patients who lack an HLA-matched donor. UCBT is less likely to produce severe GVHD compared to bone marrow 
transplantation, and thus has the advantage of allowing for greater HLA disparity between donor and recipient. Its disadvantage, however, is the significantly lower cell dose in UCB when compared to PBSC or BM (the cell dose in one average UCB unit is $1 / 10$ of a typical BM allograft and $1 / 100$ of a PBSC allograft), predictably resulting in a longer time to engraftment, and potentially greater early post-transplant complications. UCB transplants have had the best results in children where a relatively high cell dose $/ \mathrm{kg}$ can be administered. There has been a greater risk of complications in adult recipients.

More than 500 adults have undergone UCBT worldwide, ${ }^{55-60}$ mainly for hematologic malignancies. Similar to the pediatric series, the majority of patients received HLAmismatched grafts and myeloablative regimens. The largest series was reported by Eurocord, and contains 108 adults, with 32 cases of ALL, with a mean follow up of 20 months. The mean age was 26 years (range 15-53 years), mean weight $60 \mathrm{~kg}$ (range $35-110 \mathrm{~kg}$ ), and mean number of nucleated cells infused $1.7 \times 10^{7} / \mathrm{kg}$. The overall one-year survival was $27 \%$. Survival for early disease stage patients was 39\% vs. $17 \%$ for those transplanted with more advanced disease. The 60 -day probability of neutrophil engraftment was $81 \%$ at a mean time of 32 days (range 13-60 days). The incidence of acute GVHD $\geq$ II was $38 \%$. Most deaths were due to infection or GVHD. These findings were corroborated by other series. The TRM at 100 days approached $43-54 \%$ for the myeloablative regimens, and $28-48 \%$ using non-myeloablative regimens, ${ }^{55}$ with main reasons for TRM being regimen-related toxicity, infection, and relapse. Nucleate cell dose was a significant variable, conferring better outcome when the cell dose was $>2 \times 10^{7} / \mathrm{kg}$ and $/$ or CD34 cells $>1.2 \times 10^{5} / \mathrm{kg}^{56,58}$ HLA disparity had less influence on EFS. ${ }^{56}$ In summary, despite cell dose limitations, UCBT on clinical protocols for may be a viable option for selected adult patients with limited treatment options. Current research in UCB expansion may help to overcome the cell dose limitations and contribute toward reducing the TRM.

\section{Source of Donor Cells: Partially matched related or matched unrelated donors}

The majority of studies indicate that the best chance for cure for refractory or high-risk ALL is allogeneic SCT with a matched related donor. Unfortunately, less than $30 \%$ of these patients have a matched sibling donor. Thus, much work continues to be done in making partially matched related donor (PMRD) and matched unrelated donor (MUD) transplantation safe and more feasible as curative therapy. Typically these transplants have been associated with a higher risk of graft rejection, GVHD, and infection. However, more precise HLA matching of donor and recipient via the use of high resolution allele-based typing for class I and II HLA molecules, has allowed selection of better matched donors; this has resulted in a progressive improvement in the incidence of severe GVHD, and survival in patients undergoing MUD transplantation. ${ }^{61}$

Two large, retrospective series compared the outcome of MUD SCT with autologous SCT. Weisdorf et al. reported the results of 517 ALL patients (median age 14 years, range 150) who received MUD-SCT and compared them to 195 patients (median age 18 years, range 1-50) who underwent autologous SCT between 1989 and 1998. The proportion of patients in CR1 vs. CR2 was similar for both groups. However, patients receiving MUD transplants had a greater frequency of high-risk karyotypes and elevated WBC count at presentation. TRM was higher in the MUD-SCT vs. the autologous SCT group ( $42 \%$ vs. $20 \%$, p=0.004). Conversely, relapse was more frequent after autologous SCT (49\% vs. $14 \%$ in CR1, $64 \%$ vs. $25 \%$ in CR2), resulting in net similar outcomes with either transplant approach. Three-year survival rates were $45-50 \%$ for patients transplanted in CR 1 and $30-40 \%$ for patients in CR2 ${ }^{62}$ The Acute Leukemia Working Party of the European Cooperative Group for Blood and Marrow Transplantation (EBMT) reported very similar outcomes. A significantly higher TRM, from GVHD and graft failure, in the MUD-SCT group was offset by a significantly higher risk of relapse in the autologous SCT group, resulting in similar 2-year LFS for both groups (39\% MUD, 32\% auto). ${ }^{63}$

Due to the small numbers of patients and differing approaches to partially matched related donor (PMRD) transplantation, little data exists for this investigational approach. Most studies suggest a higher rate of rejection and acute GVHD, but similar overall survival for patients with donors matched for 5 of the 6 HLA A, B and DR antigens as with fully matched sibling donors. ${ }^{64}$ Greater degrees of mismatch are associated for higher risks of rejection, GVHD and treatment related mortality, and an autologous SCT may become preferable in the absence of an HLA-matched donor. ${ }^{65}$ In summary, the decision to proceed with MUD or autologous transplantation, or to proceed with other "Phase I" approaches for these high-risk patients currently remains very complex, and should be based on the specific situation of each individual patient.

\section{The Role of T-cell Depletion}

Studies have shown consistently that a major therapeutic effect of allogeneic SCT is derived from the GVM effect, with a reduced risk of relapse noted in patients with GVHD. The major difficulty lies in separating the beneficial GVM effect from the adverse consequences of GVHD. GVHD is primarily mediated by donor derived Tlymphocytes. One approach to prevent acute GVHD, is to deplete T-cells from the donor marrow or PBSC. After initial immune reconstitution, donor T-lymphocytes (DLI) can be administered with a lower risk of GVHD to enhance the GVM anti-leukemic effect. As described previously, Campath-1H, directed against the CD52 antigen, provides a novel approach for both ex vivo and in vivo T-cell purging. 
The role of T-cell depleted SCT remains controversial. While T-cell depleted SCT are associated with a lower incidence of acute and chronic GVHD, GVM effects may be reduced and leukemia free survival has not been improved in controlled trials for either matched sibling or unrelated donor transplants. Several groups have reported a decreased risk of relapse with T-cell depleted SCT by manipulating the preparative regimen to compensate for potential lack of a GVM effect, reporting EFS rates up to 64\%, which compare very favorably with non T-cell depleted transplants. ${ }^{66,67}$

\section{Immunomodulation with DLI}

Table 4 summarizes results obtained from both single institution and registry data, and demonstrates a consistent decrease in relapse rates for patients who develop GVHD vs. those who do not. ${ }^{19,68,69} \mathrm{~A}$ GVM effect that is associated with the presence of GVHD has been described in ALL, AML, and CML; interestingly this effect appears most potent in ALL and is reflected by the data in Table $4 .{ }^{70}$ However, in distinct contrast to observations of the benefit of GVHD in reducing the relapse rate, there is a marked absence of a significant GVM effect in ALL following DLI. In contrast to CML and AML where DLI often results in complete remissions in patients with relapsed disease following allogeneic transplant, DLI does not appear to be effective for ALL with relapse following an allogeneic transplant. ${ }^{71}$

\section{Table 4}

Risk of relapse following non-T-cell depleted allogeneic transplantation in ALL

\begin{tabular}{cccc}
\hline Study & Number of Patients & Risk of Relapse & $(\%)$ \\
\hline Doney, 199120 & 192 (SCT in CR2) & $\begin{array}{c}\text { No GVHD } \\
\text { Grade II-IV GVHD }\end{array}$ & 80 \\
& & No GVHD & 40 \\
Sullivan, 198972 & \multirow{2}{*}{ 200 (SCT in CR) } & $\begin{array}{c}\text { acute GVHD } \\
\text { acute \& chronic GVHD }\end{array}$ & 27 \\
& & No GVHD & 22 \\
& (SCT in relapse) & acute GVHD & 81 \\
& & acute \& chronic GVHD & 43 \\
& & No GVHD & 44 \\
Horowitz, 199073 & \multirow{2}{*}{349 (SCT in CR1) } & acute GVHD & 17 \\
(IBMTR) & & chronic GVHD & 20 \\
& & acute \& chronic GVHD & 15
\end{tabular}

\section{Long-term Complications of Allogeneic SCT}

Socie et al analyzed the characteristics of 6691 patients listed in the IBMTR who underwent allogeneic SCT for hematologic malignancies between January 1980 and December 1993. ${ }^{72}$ The median duration of follow-up was 80 months. Mortality rates in this cohort were compared with those of an age-, sex-, and nationality-matched general population. For ALL patients, the relative mortality rate was 20.1 two years after transplantation, 25.9 five years after transplantation, and 15.4 ten years after transplantation. Not surprisingly, recurrent leukemia was the chief cause of death with older age associated with an increased risk of relapse in the ALL group ( $48 \%$ vs. $11 \%$ relapses in the overall group). Chronic GVHD was the second leading cause of death overall, with $23 \%$ observed in the ALL cohort. The incidence of secondary cancers was $10 \%$ in the ALL group.

Quality of life and psychosocial functioning are major issues following allogeneic SCT. Broers et al evaluated quality of life in a prospective study of 125 consecutive patients who underwent BMT between 1987 and 1992. ${ }^{73}$ Patients were evaluated with questionnaires measuring quality of life, functional limitations, psychological distress, anxiety, depression, and self-esteem. Nearly $90 \%$ of patients reported a good to excellent quality of life at 3 years. Changes in quality of life and psychological distress could be explained entirely by changes in functional limitations and somatic symptoms. One such limitation is the late neurotoxic effects of BMT on cognitive functioning. Harder et al investigated this phenomenon in a consecutively treated cohort of long-term adult survivors. ${ }^{74}$ All received total body irradiation up to 12 Gy. Assessment took place 22-82 months after BMT. Mild to moderate cognitive impairment was found in $60 \%$ of patients. Compared with healthy population norms, selective attention and executive function, information processing speed, verbal learning, and verbal and visual memory were most likely to be affected. Therefore, cognitive functioning should be used as an outcome parameter in BMT studies, and emphasis should be placed on interventions that help patients cope with their physical limitations.

\section{Conclusion}

In conclusion, allogeneic SCT has been demonstrated to have a major therapeutic benefit for selected patients with high-risk ALL. However, much work remains to be done to improve survival for patients with this challenging disease. Results of trials of novel strategies are eagerly awaited including the incorporation of molecularly targeted chemotherapy, targeted immunotherapy using monoclonal antibodies or adoptive cellular therapy, and novel non-myeloablative preparative regimens with promise to decrease treatment-related morbidity and improve survival.

\section{Resumo}

Enquanto pacientes adultos com leucemia linfoblástica aguda (LLA) podem alcançar taxas de remissão completa $(R C)$ de até $90 \% \mathrm{com}$ regimes quimioterápicos intensivos, somente 25-50\% destes pacientes mantêm remissão em prazos longos. Esforços de pesquisas atuais focam estratégias inovadoras pós-remissão com o objetivo de melhorar a sobrevida livre de doença e sobrevida global. A identificação dos grupos prognósticos diferentes com base na biologia da mutação maligna e os padrões clínicos da apresentação da 
doença permitem terapia adaptada ao risco. Ensaios múltiplos randomizados têm mostrado que transplante das células hematopoiéticas melhora os resultados dos pacientes com LLA de alto risco. Entre os pacientes de alto risco, a presença da doença na hora do transplante das células progenitoras e a fonte destas células utilizadas, têm um grande impacto em sobrevivência. A incorporação de anticorpos monoclonais no regime preparativo pode melhorar a eficácia do procedimento. O uso das infusões de linfócitos do doador está ainda sobre investigação nestes pacientes. Rev. bras. hematol. hemoter. 2005;27(1):61-69.

Palavras-chave: Leucemia linfoblástica aguda; transplante alogênico de células progenitoras; fatores prognósticos.

\section{References}

1. Kantarjian HM et al. Results of treatment with hyper-CVAD, a dose-intensive regimen, in adult acute lymphocytic leukemia. J Clin Oncol 2000;18(3):547-61.

2. Linker $\mathrm{C}$ et al. Intensified and shortened cyclical chemotherapy for adult acute lymphoblastic leukemia. J Clin Oncol 2002 20(10): 2.464-71.

3. Larson RA. Recent clinical trials in acute lymphocytic leukemia by the Cancer and Leukemia Group B. Hematol Oncol Clin North Am 2000;14(6): 1.367-79, x.

4. Hoelzer D et al. Prognostic factors in a multicenter study for treatment of acute lymphoblastic leukemia in adults. Blood 1988; 71(1):123-31.

5. Charrin $\mathrm{C}$ and F. Mugneret, [Cytogenetics of recurrent acute leukemia]. Rev Prat 1996;46(1):37-41.

6. Faderl $\mathrm{S}$ et al. Clinical significance of cytogenetic abnormalities in adult acute lymphoblastic leukemia. Blood 1998;91(11):3.995-4.019.

7. Wetzler $M$ et al. Prospective karyotype analysis in adult acute lymphoblastic leukemia: the cancer and leukemia Group B experience. Blood 1999;93(11):3.983-93.

8. Wetzler M. Cytogenetics in adult acute lymphocytic leukemia. Hematol Oncol Clin North Am 2000;14(6):1.237-49.

9. Stock $W$ and $Z$. Estrov. Studies of minimal residual disease in acute lymphocytic leukemia. Hematol Oncol Clin North Am 2000; 14(6):1.289-305, viii-ix.

10. Hoelzer D. Acute Lymphoblastic Leukemia. In American Society of Hematology. 2002. Pennsylvania.

11. Radich JP et al. Polymerase chain reaction detection of the BCR$\mathrm{ABL}$ fusion transcript after allogeneic marrow transplantation for chronic myeloid leukemia: results and implications in 346 patients. Blood 1995;85(9):2.632-8.

12. Gehly GB et al. Chimeric BCR-abl messenger RNA as a marker for minimal residual disease in patients transplanted for Philadelphia chromosome-positive acute lymphoblastic leukemia. Blood 1991; 78(2):458-65.

13. Mitterbauer G. et al. Quantification of minimal residual disease in patients with BCR-ABL-positive acute lymphoblastic leukaemia using quantitative competitive polymerase chain reaction. $\mathrm{Br} \mathrm{J}$ Haematol 1999;106(3):634-43.

14. Miyamura K et al. Detection of Philadelphia chromosome-positive acute lymphoblastic leukemia by polymerase chain reaction: possible eradication of minimal residual disease by marrow transplantation. Blood 1992;79(5):1.366-70.

15. Preudhomme $\mathrm{C}$ et al. Good correlation between RT-PCR analysis and relapse in Philadelphia (Ph1)-positive acute lymphoblastic leukemia (ALL). Leukemia 1997;11(2):294-8.

16. Blaise D et al. Allogeneic or autologous bone marrow transplantation for acute lymphoblastic leukemia in first complete remission. Bone Marrow Transplant 1990;5(1):7-12.

17. Chao NJ et al. Allogeneic bone marrow transplantation for highrisk acute lymphoblastic leukemia during first complete remission. Blood 1991;78(8):1.923-7.
18. De Witte $\mathrm{T}$ et al. Role of allogenic bone marrow transplantation in adolescent or adult patients with acute lymphoblastic leukaemia or lymphoblastic lymphoma in first remission. Bone Marrow Transplant 1994;14(5):767-74.

19. Doney K et al. Treatment of adult acute lymphoblastic leukemia with allogeneic bone marrow transplantation. Multivariate analysis of factors affecting acute graft-versus-host disease, relapse, and relapse-free survival. Bone Marrow Transplant 1991;7(6):453-9.

20. Sutton L et al. Allogeneic bone marrow transplantation for adult acute lymphoblastic leukemia in first complete remission: factors predictive of transplant-related mortality and influence of total body irradiation modalities. Bone Marrow Transplant 1993;12(6):583-9.

21. Vey $\mathrm{N}$ et al. Bone marrow transplantation in 63 adult patients with acute lymphoblastic leukemia in first complete remission. Bone Marrow Transplant 1994;14(3):383-8.

22. Wingard JR et al. Allogeneic bone marrow transplantation for patients with high-risk acute lymphoblastic leukemia. J Clin Oncol 1990;8(5):820-30.

23. Sebban $\mathrm{C}$ et al. Allogeneic bone marrow transplantation in adult acute lymphoblastic leukemia in first complete remission: a comparative study. French Group of Therapy of Adult Acute Lymphoblastic Leukemia. J Clin Oncol 1994; 12(12):2.580-7.

24. Thiebaut A et al. Adult acute lymphocytic leukemia study testing chemotherapy and autologous and allogeneic transplantation. A follow-up report of the French protocol LALA 87. Hematol Oncol Clin North Am 2000;14(6):1.353-66, x.

25. Rowe J. Favorable results of allogeneic bone marrow transplantation (BMT) for adults with Philadelphia (Ph)-chromosome-negative Acute Lymphoblastic Leukemia (ALL) in first complete remission (CR): Results from the International ALL Trial (MRC UKALL XII/ECOG E2993). Blood 2001;98:2009a.

26. Report from the International Bone Marrow Transplant Registry. Advisory Committee of the International Bone Marrow Transplant Registry. Bone Marrow Transplant 1989;4(3):221-8.

27. Barrett AJ et al. Marrow transplantation for acute lymphoblastic leukemia: factors affecting relapse and survival. Blood 1989;74(2): 862-71.

28. Greinix HT et al. Leukemia-free survival and mortality in patients with refractory or relapsed acute leukemia given marrow transplants from sibling and unrelated donors. Bone Marrow Transplant 1998; 21(7):673-8.

29. Michallet M et al. Second allogeneic haematopoietic stem cell transplantation in relapsed acute and chronic leukaemias for patients who underwent a first allogeneic bone marrow transplantation: a survey of the Societe Francaise de Greffe de moelle (SFGM). Br J Haematol 2000;108(2):400-7.

30. Forman SJ et al. Allogeneic bone marrow transplantation as therapy for primary induction failure for patients with acute leukemia. J Clin Oncol 1991;9(9):1.570-4.

31. Biggs JC et al. Bone marrow transplants may cure patients with acute leukemia never achieving remission with chemotherapy. Blood 1992;80(4):1.090-3.

32. Martino $\mathrm{R}$ et al. Intensive salvage chemotherapy for primary refractory or first relapsed adult acute lymphoblastic leukemia: results of a prospective trial. Haematologica 1999;84(6):505-10.

33. Druker BJ et al. Activity of a specific inhibitor of the $B C R-A B L$ tyrosine kinase in the blast crisis of chronic myeloid leukemia and acute lymphoblastic leukemia with the Philadelphia chromosome. N Engl J Med 2001;344(14):1.038-42.

34. Thomas DA et al. Primary refractory and relapsed adult acute lymphoblastic leukemia: characteristics, treatment results, and prognosis with salvage therapy. Cancer 1999;86(7):1.216-30.

35. Thomas DA et al. Treatment of Philadelphia chromosome-positive acute lymphocytic leukemia with hyper-CVAD and imatinib mesylate. Blood 2004;103(12):4.396-407.

36. Goldstone AH PH, Durrant J et al. Allogeneic transplant (Related or Unrelated Donor) is the preferred treatment for adult Philadelphia Chromosome Positive $(\mathrm{Ph}+)$ Acute Lymphoblastic Leukemia (ALL). Results from the International ALL Trial (MRC UKALLXII/ECOG E2993). in American Society of Hematology. 2001. Orlando, Florida: Blood. 
37. Snyder DS et al. Long-term follow-up of 23 patients with Philadelphia chromosome-positive acute lymphoblastic leukemia treated with allogeneic bone marrow transplant in first complete remission. Leukemia 1999;13(12):2.053-8.

38. Stockschlader $\mathrm{M}$ et al. Bone marrow transplantation for Philadelphiachromosome-positive acute lymphoblastic leukemia. Bone Marrow Transplant 1995;16(5):663-7.

39. Dunlop LC et al. Bone marrow transplantation for Philadelphia chromosome-positive acute lymphoblastic leukemia. Bone Marrow Transplant 1996;17(3):365-9.

40. Sierra J et al. Marrow transplants from unrelated donors for treatment of Philadelphia chromosome-positive acute lymphoblastic leukemia. Blood 1997;90(4):1410-4

41. Keil F et al. Relapse of Philadelphia chromosome positive acute lymphoblastic leukaemia after marrow transplantation: sustained molecular remission after early and dose-escalating infusion of donor leucocytes. Br J Haematol 1997;97(1):161-4.

42. Yazaki M et al. Successful prevention of hematological relapse for a patient with Philadelphia chromosome-positive acute lymphoblastic leukemia after allogeneic bone marrow transplantation by donor leukocyte infusion. Bone Marrow Transplant 1997;19(4):393-4.

43. Woods WG et al. Bone marrow transplantation for acute lymphocytic leukemia utilizing total body irradiation followed by high doses of cytosine arabinoside: lack of superiority over cyclophosphamidecontaining conditioning regimens. Bone Marrow Transplant 1990;6(1):9-16.

44. Blume KG et al. Total body irradiation and high-dose etoposide: a new preparatory regimen for bone marrow transplantation in patients with advanced hematologic malignancies. Blood 1987; 69(4):1.015-20.

45. Matthews DC et al. Phase I study of (131)I-anti-CD45 antibody plus cyclophosphamide and total body irradiation for advanced acute leukemia and myelodysplastic syndrome. Blood 1999;94(4): $1.237-47$.

46. Buchmann I et al. Myeloablative radioimmunotherapy with Re188-anti-CD66-antibody for conditioning of high-risk leukemia patients prior to stem cell transplantation: biodistribution, biokinetics and immediate toxicities. Cancer Biother Radiopharm 2002;17(2):151-63.

47. Copelan EA and Deeg HJ. Conditioning for allogeneic marrow transplantation in patients with lymphohematopoietic malignancies without the use of total body irradiation. Blood $1992 ; 80(7): 1.648-58$

48. Gokbuget N and Hoelzer D. Treatment with monoclonal antibodies in acute lymphoblastic leukemia: current knowledge and future prospects. Ann Hematol 2004;83(4):201-5.

49. Dinndorf Pet al. Phase I trial of anti-B4-blocked ricin in pediatric patients with leukemia and lymphoma. J Immunother 2001; 24(6):511-6.

50. Szatrowski TP et al. Lineage specific treatment of adult patients with acute lymphoblastic leukemia in first remission with anti-B4blocked ricin or high-dose cytarabine: Cancer and Leukemia Group B Study 9311. Cancer 2003;97(6):1.471-80.

51. Novitzky $\mathrm{N}$ et al. Ex vivo depletion of $\mathrm{T}$ cells from bone marrow grafts with CAMPATH-1 in acute leukemia: graft-versus-host disease and graft-versus-leukemia effect. Transplantation 1999; 67(4):620-6.

52. Martino R et al. Allogeneic hematopoietic stem cell transplantation with reduced-intensity conditioning in acute lymphoblastic leukemia: a feasibility study. Haematologica 2003;88(5):555-60.

53. Giralt $\mathrm{S}$ et al. Melphalan and purine analog-containing preparative regimens: reduced-intensity conditioning for patients with hematologic malignancies undergoing allogeneic progenitor cell transplantation. Blood 2001;97(3):631-7.

54. Champlin RE et al. Blood stem cells compared with bone marrow as a source of hematopoietic cells for allogeneic transplantation. IBMTR Histocompatibility and Stem Cell Sources Working Committee and the European Group for Blood and Marrow Transplantation (EBMT). Blood 2000;95(12):3.702-9.

55. Barker JN et al. Rapid and complete donor chimerism in adult recipients of unrelated donor umbilical cord blood transplantation after reduced-intensity conditioning. Blood 2003;102(5):1.915-9.

56. Laughlin MJ et al. Hematopoietic engraftment and survival in adult recipients of umbilical-cord blood from unrelated donors. $\mathrm{N}$ Eng1 J Med 2001;344(24):1.815-22.

57. Sanz GF et al. Standardized, unrelated donor cord blood transplantation in adults with hematologic malignancies. Blood 2001;98(8):2.332-8.

58. Gluckman E, V. Rocha, and S. Chevret. Results of unrelated umbilical cord blood hematopoietic stem cell transplantation. Rev Clin Exp Hematol 2001;5(2):87-99.

59. Cornetta K. Umbilial cord blood transplantation in adults: results of a prospective, multi-institutional, NHBLI sponsored trial. Blood 2002;100(11):146a.

60. Iseki $\mathrm{T}$. Unrelated cord blood transplantation in adults with hematologic malignancies: a single institution study. Blood 2001; 98(11):2729a.

61. Petersdorf EW et al. Optimizing outcome after unrelated marrow transplantation by comprehensive matching of HLA class I and II alleles in the donor and recipient. Blood 1998;92(10):3.515-20.

62. Weisdorf D et al. Autologous versus allogeneic unrelated donor transplantation for acute lymphoblastic leukemia: comparative toxicity and outcomes. Biol Blood Marrow Transplant 2002;8(4): 213-20.

63. Ringden Oet al. Donor search or autografting in patients with acute leukaemia who lack an HLA-identical sibling? A matched-pair analysis. Acute Leukaemia Working Party of the European Cooperative Group for Blood and Marrow Transplantation (EBMT) and the International Marrow Unrelated Search and Transplant (IMUST) Study. Bone Marrow Transplant 1997;19(10):963-8.

64. Beatty PG et al. Marrow transplantation from related donors other than HLA-identical siblings. N Engl J Med 1985;313(13): 765-71.

65. Singhal S et al. Haploidentical vs autologous hematopoietic stem cell transplantation in patients with acute leukemia beyond first remission. Bone Marrow Transplant 2003;31(10):889-95.

66. Aversa F et al. Improved outcome with T-cell-depleted bone marrow transplantation for acute leukemia. J Clin Oncol 1999; 17(5):1.545-50.

67. Schattenberg A et al. Outcome of T cell-depleted transplantation after conditioning with an intensified regimen in patients aged 50 years or more is comparable with that in younger patients. Bone Marrow Transplant 2000;26(1):17-22.

68. Sullivan KM et al. Influence of acute and chronic graft-versus-host disease on relapse and survival after bone marrow transplantation from HLA-identical siblings as treatment of acute and chronic leukemia. Blood 1989;73(6):1.720-8.

69. Horowitz MM et al. Graft-versus-leukemia reactions after bone marrow transplantation. Blood 1990;75(3):555-62.

70. Appelbaum FR. Graft versus leukemia (GVL) in the therapy of acute lymphoblastic leukemia (ALL). Leukemia 1997;11 Suppl 4: p. S15-7.

71. Collins RH Jr. et al. Donor leukocyte infusions in 140 patients with relapsed malignancy after allogeneic bone marrow transplantation. J Clin Oncol 1997;15(2):433-44.

72. Socie $G$ et al. Long-term survival and late deaths after allogeneic bone marrow transplantation. Late Effects Working Committee of the International Bone Marrow Transplant Registry. N Engl J Med 1999;341(1):14-21.

73. Broers $\mathrm{S}$ et al. Psychological functioning and quality of life following bone marrow transplantation: a 3-year follow-up study. J Psychosom Res 2000;48(1):11-21.

74. Harder $\mathrm{H}$ et al. Cognitive functioning and quality of life in longterm adult survivors of bone marrow transplantation. Cancer 2002;95(1):183-92.

Avaliação: Editor e dois revisores externos.

Conflito de interesse: não declarado

Recebido: 14/01/05

Aceito após modificações: 02/02/05 